\title{
Estudo de Impacto Ambiental e Capacidade de Carga na Trilha do Paraíso, Situada na Serra do Japi, Jundiaí - SP - Brasil
}

\section{Environmental Impacts and Carrying Capacity: a study of the Paradise Trail, situated in Serra do Japi, Jundiaí - SP - Brazil}

Joseane Violi

RESUMO: O ecoturismo surgiu como um desejo de usufruir a paisagem, seguido pela preocupação e conscientização com o meio ambiente, e visa à responsabilidade com a sustentabilidade, a educação do visitante por meio da interpretação da natureza, e os benefícios às comunidades locais. Para prevenir as áreas protegidas de impactos ambientais, é necessário que se elabore um planejamento para o local com o objetivo de alcançar um desenvolvimento sustentável para o patrimônio natural. Será realizada uma análise da paisagem, onde se verificará o impacto ambiental causado pela visitação na trilha do Paraíso, realizando estudo de capacidade de carga com a intenção de estabelecer um limite à utilização de tal trilha, a fim de que esta não resulte em deterioração ambiental. Para esta pesquisa, foram selecionados os métodos de Bruschi et al., Magro e Cifuentes.

PALAVRAS-CHAVE: ecoturismo; impacto ambiental; trilha; capacidade de carga; Serra do Japi.

ABSTRACT: The ecotourism appeared as a desire to usufruct the landscape, followed for the concern and awareness with the environment, and aims responsibility with sustainment, the education of the visitor through the interpretation of the nature, and the benefits to the local communities. To prevent the protecting areas of environmental impacts, it is necessary to have a plan for the place with the objective to reach a sustainable development for the natural patrimony. An analysis of the landscape will be carried through,

1. Graduanda em Turismo na PuC - Campinas. Contato: Caixa Postal 1096 - 13202-970 - Jundiaísp; e-mail: josy_violi@ig.com.br. 
where the environmental impact caused by the visitation in the trail of the Paradise will be verified, carrying through study of load capacity with the intention to establish a limit to the use of such trail, so that this does not result in environmental deterioration. For this research, had been selected the methods of Bruschi et al, Magro and Cifuentes.

KEYWORDS: ecotourism; environmental impact; trail; carrying capacity; Serra do Japi.

\section{Introdução}

\section{O ecoturismo}

A necessidade de atividades de recreação e lazer, assim como o turismo, vem acompanhando a vida do homem desde os tempos antigos, porém vem sofrendo diferenciações de tempos em tempos (Tulik apud Pezotta, 2002).

A embratur (1994) define ecoturismo como sendo "um segmento da atividade turística que utiliza, de forma sustentável, o patrimônio natural e cultural, incentiva sua conservação e busca a formação de uma consciência ambientalista através da interpretação do ambiente, promovendo o bem-estar das populações envolvidas". Tem como fundamentos:

- promover e desenvolver o turismo com bases cultural e ecologicamente sustentáveis;

- promover e incentivar investimentos em conservação dos recursos culturais e naturais utilizados;

- fazer com que a conservação beneficie materialmente comunidades envolvidas, pois somente servindo de fonte de renda alternativa estas se tornarão aliadas de ações conservacionistas;

- ser operado de acordo com critérios de mínimo impacto e ser uma ferramenta de proteção e conservação ambiental e cultural;

- educar e motivar pessoas por meio da participação e atividades a perceber a importância de áreas naturais e culturalmente conservadas.

Nesse sentido, três grandes eixos temáticos sustentam o conceito brasileiro de ecoturismo: a sustentabilidade, a educação do visitante e os benefícios às comunidades locais. A questão da educação do visitante deve ser entendida num sentido mais amplo, no contexto de que o turismo deve ser sempre informativo e educacional (Mitraud, 2003).
A interpretação da natureza é um componente fundamental da experiência dos visitantes em áreas protegidas. É a ponte de comunicação que liga os visitantes aos recursos e leva as pessoas a um novo e fascinante mundo, propiciando novo entendimento, novas idéias, novo entusiasmo e novos interesses. Um bom programa de interpretação procura afetar não somente comportamentos imediatos, mas principalmente as crenças e atitudes dos visitantes (Kinker, 2002). Segundo Ceballo-Lascuráin (apud Kinker, 2002), o programa de interpretação pode enriquecer muito a experiência do visitante, pois permite que esse entenda melhor o que está vivenciando, relacionando os conteúdos da interpretação com a experiência.

Por esse motivo, o governo, juntamente ao IBAMA, vem dando proteção a diversas áreas representativas dos ecossistemas brasileiros, tentando garantir a diversidade biológica com a criação de parques nacionais e áreas de proteção, buscando possibilidades para o desenvolvimento regional, além de programas para a melhoria do ecoturismo por meio da capacitação e do treinamento de comunidades locais e equipes que guiariam os turistas pela área de visitação (Diegues, 1999; Mourão, 2000; Santos, 2000 apud Pezotta, 2002).

Trilhas

Guillaumon et al., (1977) definem trilhas como sendo "percursos traçados em um sítio natural que propiciem explicações sobre o meio ambiente (flora, fauna e fenômenos naturais)".

A principal função das trilhas sempre foi a de suprir a necessidade de deslocamento. No entanto, elas surgem como novo meio de contato entre o homem e a natureza, porém este contato provoca tanto impacto físico como visual, sonoro e olfativo.

As trilhas oferecem aos visitantes a oportunidade de desfrutar de uma área de maneira tranqüila e alcançar maior familiaridade com o meio natural. Trilhas bem construídas e devidamente mantidas protegem o ambiente do impacto do uso, e ainda asseguram aos visitantes maior conforto, segurança e satisfação (Andrade, 2003).

Essas trilhas, conhecidas como trilhas de interpretação, têm como função principal a educação ambiental, trabalhando com a interação entre o homem e o meio, relacionando a situação da flora e da fauna com os impactos humanos. Além disso, é um local de fuga e restabelecimento racional que proporciona calma e relaxamento aos moradores urbanos. As trilhas também complemen- 
tam de maneira prática as aulas de ciências biológicas das escolas (Guillaumon et al., 1977)

\section{Impactos}

As áreas naturais, em particular as áreas protegidas legalmente, sua paisagem, fauna e flora, juntamente com os elementos culturais existentes, constituem grandes atrações, tanto para os habitantes dos países aos quais as áreas pertencem quanto para turistas de todo o mundo. Por esse motivo, as organizações para a conservação reconhecem a enorme relevância do turismo e estão cientes dos inúmeros danos que um turismo mal administrado ou sem controle pode provocar nos patrimônios natural e cultural do planeta (Lindberg \& Hawkins, 2001).

Os impactos ambientais são muitos e, segundo Ruschmann (1997),

os impactos do turismo referem-se à gama de modificações ou à seqüência de eventos provocados pelo processo do desenvolvimento turístico nas localidades receptoras. As variáveis que provocam os impactos têm natureza, intensidade, direções e magnitudes diversas; porém, os resultados interagem e săo geralmente irreversíveis.

O impacto teórico do ecoturismo pode ser conhecido por meio de dois itens relevantes: os custos potenciais, que são a degradação do meio ambiente, as injustiças e instabilidades econômicas, as mudanças socioculturais negativas; e os benefícios potenciais, que são a geração de receita para as áreas protegidas, a criação de empregos para as pessoas que vivem próximas a essas áreas e a promoção da educação ambiental e da conscientização sobre a conservação (Boo, 2001).

Uma forma de manter a relação homem-natureza é o ser humano admitir os prejuízos que causa ao meio ambiente, mesmo quando bem-intencionado, $e$ manter um acompanhamento constante, nas APAs, das condições ambientais. Somente desse modo a atividade turística pode contribuir para gerar uma série de inversões, no meio ambiente, que resultarão na conservação do meio e na manutenção e possível incremento de novas correntes turísticas nas áreas nas quais se aplique uma política de sustentabilidade, com a melhora da paisagem e a conservação dos recursos naturais (Dias \& Aguiar, 2002).

A visitação causa alterações no ambiente natural. É necessário adotar medidas de controle para protegê-lo, e ao mesmo tempo assegurar qualidade à visita (Mitraud, 2003).
O ecoturismo, mais do que qualquer outra forma de turismo na natureza, depende da qualidade do ambiente visitado. Esse é mais um motivo pelo qual a atividade deve ser controlada e seus potenciais impactos negativos devem ser minimizados pelo manejo (Kinker, 2002).

A fim de prevenir os impactos ambientais causados pelo turismo, deve-se elaborar um planejamento para o local com o objetivo de alcançar um desenvolvimento sustentável para o patrimônio natural e para todos os produtos que estão envolvidos, tais como seus atrativos e equipamentos turísticos (Wearing, 2001).

\section{Capacidade de carga}

A capacidade de suporte ou carga foi definida por Beni (2001) como

o número máximo anual de visitantes que o atrativo turístico natural pode suportar, sem sofrer alterações, considerando-se o equilíbrio dinâmico entre ambiente, quantidade de turistas e qualidade dos serviços instalados.

Seu estabelecimento se dá para áreas de recreação, lazer e pesquisas, visando limitar o uso sem causar alterações ambientais no local de visitação (Faria \& Lutgens, 1997; Binelli et al., 1997).

A capacidade de carga desenvolveu-se com o objetivo de gerar um indicador quantitativo, uma espécie de "termômetro" para os gestores de áreas onde nunca se fez o acompanhamento sistemático dos impactos de visitação: os gestores da área devem manter o número de visitantes em uma área protegida abaixo da capacidade de carga estabelecida. Porém, não é um número mágico cujo cumprimento absoluto resolve e previne todo e qualquer impacto inaceitável. Muitas vezes o tipo de uso e o comportamento do visitante são fatores que oferecem um risco muito mais elevado do que a quantidade de visitantes (Mitraud, 2003). Podese dizer que é

um instrumento indispensável para identificar as situações críticas que necessitam de cuidados e medidas especiais para saná-las, para prevenir problemas a partir da aplicação de controles prévios e para promover o desenvolvimento sustentável do turismo (Ruschmann,1997)

O planejamento ambiental para fins ecoturísticos compreende a capacidade de carga como instrumento de determinação do quantitativo de visitação, monitoramento e gestão dos impactos de visitação turística, sendo de indispensável importância para um programa de visitação (Cooper et al., 2001). 
Segundo Faria e Lutgens (1997), no Brasil e em outros países em desenvolvimento da América Latina, existem poucas iniciativas para se estabelecer limites de visitação a partir de metodologias coerentes. Em seu lugar, existem implantações de limites estabelecidos de maneira subjetiva, não confiáveis e pouco práticos.

No contexto do planejamento, significa que o desenvolvimento deve ser norteado para não exceder a capacidade do meio ambiente, para não esgotá-lo ou destruí-lo (Oliveira, 2003).

Este projeto consiste na análise dos impactos ambientais e na determinação da capacidade de carga de uma trilha na Serra do Japi, cuja finalidade será determinar o grau de interferência no meio e analisar se o programa de visitação está sendo realizado de maneira adequada à conservação do meio ambiente.

\section{Serra do Japi}

A Serra do Japi é um dos poucos remanescentes de Mata Atlântica ainda existentes no interior do Estado de São Paulo, pertencentes aos municípios de Jundiaí, Cabreúva, Cajamar e Pirapora do Bom Jesus (Morellato, 1992).

Para Jundiaí, a Serra representa um grande patrimônio ambientale foi transformada em Área de Proteção Ambiental - APA em 16 de maio de 1984.

A resolução no 10/88 do Conselho Nacional do Meio Ambiente - CONAMA, refere-se às Áreas de Proteção Ambiental - APAs como Unidade de Conservação destinada a proteger e conservar a qualidade ambiental e os sistemas naturais ali existentes, visando a melhoria da qualidade de vida da comunidade local e a proteção dos ecossistemas regionais (Candido, 2003).

As reservas da natureza constituem monumentos naturais e amostras representativas da biodiversidade, ali está presente um sem-número de espécies raras, endêmicas e ameaçadas de extinção (Seabra, 2001).

Jundiaí possui o "Programa de Visitas Monitoradas à Serra do Japi", que já completa o seu terceiro ano com aproximadamente três mil visitas realizadas, em que há passeios agendados a quatro trilhas guiadas (Trial, Jardim Serra da Ermida, Mirante e Paraíso), "que requerem a presença de um intérprete treinado, que acompanha os visitantes na caminhada levando-os a observar, sentir, experimentar, questionar e descobrir" (Novaes, 2002). Os grupos são acompanhados por monitores que passaram por capacitações e qualificações por meio de seleção em concurso público. Esses monitores também são conhecidos como fiscalizadores da
Serra, onde realizam projetos de minimização de impacto ambiental causado por visitantes e donos de propriedades na Serra, introduzindo o replantio de árvores que estavam desaparecendo do meio.

As informações a seguir são baseadas em dados obtidos na Secretaria de Planejamento e Meio Ambiente de Jundiaí (2004) e no Caderno de Planejamento/Serra do Japi (2000).

A Serra do Japi é caracterizada por elevações de topos relativamente aplainados e encostas bastante íngremes, com altitudes variando entre 700 e 1.291 metros, pertencentes a um conjunto montanhoso conhecido por serrania de São Roque. Seu solo é formado, principalmente, por quartzitos e, em menores proporções, aparecem rochas como granitos, anfibolitos, gnaisses e migmatitos.

As temperaturas médias anuais estão entre $15,7^{\circ} \mathrm{Ce} 19,2^{\circ} \mathrm{C}$, nas partes mais altas e mais baixas respectivamente, sendo o mês de julho o mais frio e o mais quente, janeiro. O período mais chuvoso vai de outubro a março; o mais seco, quando os riscos de incêndios são maiores, correspondem ao inverno.

$\mathrm{Na}$ Serra do Japi existem regiões com clima, solo e relevo bastante diferentes entre si. Também por esse motivo, ela abriga uma diversidade biológica muito grande, o que, além de tantos outros benefícios, lhe confere uma rara beleza.

Em relação à fauna, são centenas de borboletas (cerca de 900 espécies catalogadas), insetos, répteis, anfíbios (anuros), aracnídeos, aves e mamíferos. Alguns dele, como a jaguatirica e a suçuarana, estão ameaçados de extinção.

Quanto à flora, existem mais de 300 espécies de árvores observadas até hoje. Alguns vegetais possuem enorme potencial de uso, inclusive medicinal.

A trilha do Paraíso possui 5.000 metros, iniciando-se no posto de controle de acesso da Guarda Municipal, e tem como finalidade a cachoeira do Paraíso.

Quando existe a intenção de abrir uma Unidade de Conservação para visitação pública, a primeira questão a ser considerada refere-se à proteção dos recursos naturais contra vandalismos, incêndios e problemas com empregados da própria unidade (Candido, 2003).

A visitação monitorada que ocorre na trilha tem como objetivos causar o menor impacto possível à reserva; servir de intermédio entre a população e o meio ambiente, podendo dar informações sobre o patrimônio ali existente; conduzir grupos fazendo com que estes criem uma conscientização ambiental e também para evitar desaparecimentos durante o percurso. A preservação do local é mantida pelos funcionários pelo seguimento de legislações e códigos de proteção ao ambiente e também com o apoio da prefeitura e de guardas florestais. 


\section{Objetivos}

\section{Objetivos gerais}

Por meio de análise da paisagem, verificar os impactos ambientais causados pela atividade turística na Serra do Japi, e mais especificamente na trilha do Paraíso, realizando estudo de capacidade de carga para tal trilha com a intenção de estabelecer um limite à sua utilização a fim de que esta não resulte em deterioração ambiental.

\section{Objetivos específicos}

- Determinar e quantificar as alterações na paisagem existentes na área.

- Analisar a visitação monitorada que está sendo realizada no local.

- Identificar as políticas que estão sendo adotadas para a preservação do local.

- Utilizar o estudo da capacidade de carga na trilha do Paraíso mostrando ser de fundamental importância para a visitação e preservação da Serra do Japi.

\section{Metodologia}

\section{Metodologia para análise da trilha}

As trilhas são classificadas quanto à função (serviços administrativos, atividades educativas e/ou recreativas, interpretação do ambiente natural e viagens de travessia), quanto à forma (circular, oito, linear e atalho) e quanto ao grau de dificuldade para trilhas guiadas (leve, regular e semipesada) e para trilhas autoguiadas (caminhada leve, semipesada e pesada) (Andrade, 2003).

Na trilha serão analisados, também, os parâmetros descritos conforme Magro (1999), que indicam seu estado de conservação:

I. Largura da trilha: é a medida da trilha feita pela utilização de uma trena estendida entre as extremidades laterais;

II. Solo exposto: área sobre influência direta de pisoteio que não apresenta cobertura vegetal ou ela se apresenta com freqüência menor a $5 \%$ (vegetação viva e musgos). Barrancos e áreas laterais não utilizados para caminhada serão descartados;
III. Declividade paralela: declividade medida ao longo da trilha, em graus, no sentido de caminhamento;

IV. Cobertura vegetal de entorno: neste parâmetro serão considerados o tipo e o estado de conservação da vegetação que contorna a trilha;

V. Estética: é a aparência da trilha e ao seu redor. Neste item tem-se: estado de conservação do aceiro, presença ou não de vegetação e lixo, grau de dificuldade do percurso, etc.;

VI. Acúmulo de lixo: além de sua relação com a estética, sua influência na poluição local também será avaliada.

A caminhada na trilha será feita com o auxílio do biólogo Ronaldo Pereira, que estará passando seu conhecimento sobre o local para a obtenção de informações atuais sobre a área visitada, e haverá também o questionário sobre as políticas adotadas para preservação do local e os projetos existentes para conservação da Serra do Japi.

\section{Metodologia para análise de impacto ambiental na paisagem}

A análise de impacto ambiental na paisagem da trilha foi elaborada conforme o método de Bruschi et al., (2002), que apresenta uma análise aritmética de propriedades da paisagem como método de quantificação de impactos ambientais sobre ecossistemas. Esse estudo é feito pela interpretação dos elementos dominantes, por meio de mapas e observação em campo. É baseado na avaliação da paisagem, em valores de acordo com as propriedades dos elementos:

propõe-se à análise de quatro propriedades da paisagem com reflexo direto sobre a qualidade ambiental do ecossistema. Duas delas estão relacionadas com a estrutura, Dominância (D) e Heterogeneidade (H); outra representa a função de interligação entre os elementos, Conectividade (c), e a última contempla a dinâmica temporal, Permanência (P) (Bruschi et al., 2002).

Dominância: $\quad$ 1- Raro, com poucas manchas e de tamanho reduzido;

2- Ocorrência com grandes manchas inseridas na paisagem;

3- Elemento dominante na paisagem.

Heterogeneidade: 1- Homogêneo;

2- Heterogêneo.

Conectividade: 1-Isolado;

2- Pouco conectado; 


$\begin{array}{ll}\text { Permanência: } & \text { 3- Muito conectado. } \\ & \text { 1- Efêmero; } \\ & \text { 2- Permanente. }\end{array}$

Para cada um dos itens, o resultado da multiplicação dos valores entre si é o VIE (Valor de Importância Ecológica) atribuído a cada elemento da paisagem, e a soma dos resultados de todos os itens nos mostra o valor total de VIE para toda a área. Dessa forma, são tabulados os valores dos viEs da área em questão, da área atingida, do percentual de área degradada e do impacto relativo sobre o vIE, calculando-se, assim, o impacto total sobre a paisagem.

A ordenação dos elementos de acordo com seus valores de VIE propicia a obtenção de um gradiente de importância entre os diversos componentes da paisagem da área estudada (Oliveira \& Alvarenga, 2002).

\section{Metodologia para análise da capacidade de carga}

A análise da capacidade de carga servirá para a obtenção de números mais precisos sobre o limite máximo de desenvolvimento e utilização dos visitantes da trilha, servindo de base para a análise sobre a visitação monitorada que está sendo realizada no local.

Sua determinação torna-se uma importante ferramenta no trabalho de manutenção das características das áreas silvestres, quando o objetivo é mantê-

las com seu potencial não comprometido pelas atividades recreacionais (Binelli et al., 1997).

Para a análise da capacidade de carga será utilizado o trabalho de Cifuentes (1992), que desenvolveu um método de avaliação muito fácil e útil, relacionando a capacidade de carga física e social. A primeira está ligada à estabilidade e diversidade do ambiente, e a outra à quantidade de pessoas possíveis em uma área (Binelli et al., 1997). Para aplicá-lo, o primeiro passo será o diagnóstico e o mapeamento do local, em escala compatível com o nível de detalhamento requerido. Será utilizado mapa de Divisão de Cartografia Digital e Geoprocessamento cedido pela Prefeitura de Jundiaí, com escala de 1:25000, contendo os seguintes itens: área de reserva biológica, área do polígono do tombamento, área da macrozona de proteção ambiental, trilhas, estradas municipais, alguns ícones e detalhamento sobre curvas de nível e cursos d'água (ver Figura 1, em Anexos).
Cifuentes (1992) desenvolveu uma metodologia de simples aplicação que considera três níveis de capacidade: capacidade de carga física, capacidade de carga real e capacidade de carga efetiva ou permissível. A primeira é definida como o limite máximo de visitantes que podem ocupar um espaço em determinado tempo; a capacidade de carga real é a capacidade de carga física corrigida por uma série de fatores que oferecem resistências ambientais, e que são definidos em função das características do lugar; e a capacidade de carga efetiva é o limite máximo de visitas permitidas em um sítio conforme a capacidade de manejo da administração (Faria \& Lutgens, 1997).

A capacidade de carga será determinada conforme adaptação deste método para a trilha do Paraíso. O método estabelece três níveis de capacidade de suporte, respectivamente:

- Capacidade de Carga Física - CCF: é o limite máximo de visitantes que podem ocupar um espaço definido em um determinado tempo;

- Capacidade de Carga Real - CCR: é identificada após a correção de valor da CCF sobre fatores de correção obtidos ao considerar variaçōes ambientais, físicas, ecológicas e de manejo;

- Capacidade de Carga Efetiva ou Permitida - CCE: é o limite máximo de visitas permissíveis segundo a capacidade de manejo - См da área.

A primeira é definida pela seguinte fórmula:

$$
\mathrm{CCF}=\mathrm{v} / \mathrm{a} \cdot \mathrm{s} \cdot \mathrm{t}
$$

Onde: $\mathrm{v} / \mathrm{a}=$ visitantes/área ocupada $\mathrm{s}=$ superfície total da trilha disponível para uso público $\mathrm{t}=$ tempo necessário para a visita

Para o cálculo da CCR utiliza-se:

$$
\mathrm{CCR}=\mathrm{CCF} \cdot \frac{100-\mathrm{FC}}{100} \cdot \frac{100-\mathrm{FC}}{100} \cdot \frac{100-\mathrm{FC}}{100}
$$

Onde os FCs são fatores limitantes da capacidade de carga física, ou seja, fatores que limitarão o número de pessoas que terão acesso à trilha. Esses fatores consideram o ambiente visitado e não o visitante em si. É um fator de correção expressado em porcentagem.

Para a determinação dos fatores de correção - FC, temos que: 


$$
\mathrm{FC}=\frac{\mathrm{Ml}}{\mathrm{Mt}} \cdot 100 \quad \text { Onde: } \mathrm{Ml}=\text { magnitude limitante da variável }
$$$$
\mathrm{Mt}=\text { magnitude total da variável }
$$

Os fatores de correção analisados foram:

1. Precipitação:levou-se em consideração os dias de chuva que tornam as visitas impossíveis ou proporcionam uma menor satisfação dos visitantes.

2. Solo: a grande maioria do solo da área da trilha do paraíso é arenoso, portanto, para este tipo de solo foi considerado um fator de correção de $10 \%$.

3. Declividade: este dado foi obtido através de uma média entre os pontos que apresentam declividade na trilha, considerando $10 \%$.

4. Erodibilidade: pode-se dizer que não há muitos pontos com erosão acentuada, devido ao fato de que o solo já está um tanto adaptado à circulação.

5. Dias não significativos para visitas ao ano: como as visitas são realizadas com escolas, pode-se afirmar que estes dias estão presentes nas férias escolares e nos fins de semana.

E a fórmula para se chegar à CCE:

$$
\mathrm{CCE}=\mathrm{CCR} \cdot \frac{\mathrm{CM}}{100}
$$

Onde см é a porcentagem de capacidade de manejo mínima, que leva em consideração a disponibilidade de pessoas, instalações, infra-estrutura, etc.

\section{Resultados}

Os resultados foram obtidos por meio de dados coletados em saídas a campo realizadas no mês de maio de 2004, com o auxílio do biólogo e monitor Ronaldo. O monitor Luis Eduardo Pontes também contribuiu com o andamento do projeto, cedendo materiais e informações a respeito do projeto de visitação monitorada, da trilha e de toda a reserva.

\section{Análise da trilha}

\section{Trilha do Paraíso}

Para se chegar à Base Ecológica da Serra do Japi, o acesso é feito pela Avenida Coronel Gumercindo Barranqueiros, bairro Malota, onde o percurso está pavimentado ao longo do trecho de 2,4 quilômetros, e o trecho seguinte de mais 5 quilômetros é de terra, possuindo manutenção precária e dificultando o acesso. A Base Ecológica é ponto de partida para a trilha do Paraíso, que é percorrida até a cachoeira do Paraíso. Durante o trajeto, o monitor ali presente realiza algumas paradas para informações aos visitantes, procurando salientar alguns atrativos e passar pequenos detalhes, desde a história do nome da Serra do Japi até um viveiro de mudas nativas, que é uma área em recuperação feita pela guarda municipal.

A trilha do Paraíso possui 5 quilômetros de extensão em sentido único, sendo a mais extensa entre as trilhas utilizadas para visitação, e pode ser percorrida em 5 horas, aproximadamente. Possui a função de atividades educativas, sendo também utilizada para pesquisas científicas. Quanto à forma, conclui-se que é uma trilha circular e de intensidade semipesada, devido à sua topografia bastante acidentada.

A largura média desta trilha é de 3 metros, e sua declividade medida é de $10 \%$, aproximadamente, já que podemos afirmar que a trilha já começa numa altitude de 1.000 metros e chega a alcançar 1.100 metros, não havendo grandes variações.

É uma trilha guiada, pois necessita de monitores para o acompanhamento, e estes incentivam a observação do meio, incorporando a educação ambiental às suas explicações.

Nos dias chuvosos as visitas são canceladas e agendadas para outra data próxima por questão de segurança dos visitantes. Quando as chuvas ocorrem inesperadamente e os visitantes já se encontram na base ecológica da Serra, a visitação à trilha é adiada e os visitantes são convidados a uma apresentação de slides e uma pequena palestra sobre educação ambiental.

A vegetação de entorno da trilha apresenta bom estado de conservação, mas existem algumas áreas em fase de recuperação devido a impactos causados no passado. 


\section{Análise do impacto ambienta}

\begin{tabular}{|l|c|c|c|c|c|}
\hline Elementos da Paisagem & D & H & C & P & VIE \\
\hline Floresta Mesófila Semidecídua & 2 & 2 & 3 & 2 & 24 \\
\hline Cursos d'água & 2 & 2 & 3 & 2 & 24 \\
\hline Lajedo Rochoso & 1 & 2 & 2 & 2 & 8 \\
\hline Valor total para o VIE & & & & & 56 \\
\hline
\end{tabular}

\begin{tabular}{|l|c|c|c|c|c|}
\hline Elementos da Paisagem & VIE & $\begin{array}{c}\text { Área Total } \\
\left(\mathbf{m}^{2}\right)\end{array}$ & $\begin{array}{c}\text { Área Atingida } \\
\left(\mathbf{m}^{2}\right)\end{array}$ & $\begin{array}{c}\% \text { da Área } \\
\text { Atingida }\end{array}$ & Perda no VIE \\
\hline Floresta Mesófila Semidecídua & 24 & 1.969 .200 & 14.940 & 0,75 & 0,18 \\
\hline Cursos d'água & 24 & 18.700 & 130 & 0,69 & 0,16 \\
\hline Lajedo Rochoso & 8 & 12.100 & 80 & 0,66 & 0,05 \\
\hline Valor total para o VIE & 56 & & & & 0,39 \\
\hline
\end{tabular}

Impacto total aproximado sobre a paisagem: $0,7 \%$ ( $\%$ de perda global do VIE).

\section{Análise da capacidade de carga}

Para se ter o resultado de capacidade de carga - CC, primeiramente foi calculada a capacidade de carga física - CCF, seguida pela real - CCR e, por fim, pela efetiva - CCE, que traz o resultado real da capacidade da trilha.

- $\mathrm{CCF}$

$$
\begin{array}{ll}
\mathrm{CCF}=\mathrm{v} / \mathrm{a} \cdot \mathrm{s} \cdot \mathrm{t} & \mathrm{v} / \mathrm{a}=1 \text { metro quadrado } \\
\mathrm{CCF}=1.5000 .5 & \mathrm{~S}=5 \text { quilometros } \\
\mathrm{CCF}=25.000 \text { pessoas } / \text { dia } & \mathrm{t}=\text { tempo necessário para percorrer a trilha }
\end{array}
$$$$
\text { - CCR }
$$

Fatores de Correção - FCS

FC de precipitação: na Serra do Japi chove em média 66 dias por ano, por isso temos:
66.8 horas $=528$ horas/ano

$F_{C P}=\frac{528}{2448} \cdot 100 \quad \mathrm{Mt}=$ quantidade de horas em funcionamento por ano

[9,5 meses +34 dias (dias utilizados nas férias) $\times 8$ horas de funcionamento

$\mathrm{FCp}=21,57 \%$

FC de solo: o solo presente na trilha é arenoso, e para este tipo de solo foi considerado o valor de 10\% (valor médio estabelecido por observação em campo). $\mathrm{FCS}=10 \%$

FC de declividade: a declividade média local foi calculada em $10 \%$, conforme estabelecido na metodologia utilizada.

$\mathrm{FCd}=10 \%$

FC de erodibilidade: não apresenta muitos pontos com erosão, podendo ser considerado um fator de correção de $5 \%$ (valor médio estabelecido por observação em campo).

FCe $=5 \%$

FC de dias não significativos para visitas por ano: o período considerado são os fins de semana e as férias escolares, já que a grande parte das visitas é realizada por escolas ( 57 dias de férias escolares, sem contar os fins de semana que são dias de visitas).

$$
\mathrm{FCV}=15,83 \%
$$

Aplicando os fatores de correção na fórmula de CCR, temos:

$$
\begin{aligned}
& \mathrm{CCR}=\mathrm{CCF} \cdot \frac{100-\mathrm{FCp}}{100} \cdot \frac{100-\mathrm{FCs}}{100} \cdot \frac{100-\mathrm{FCd}}{100} \cdot \frac{100-\mathrm{FCe}}{100} \cdot \frac{100-\mathrm{FCv}}{100} \\
& \mathrm{CCR}=25.000 \cdot \frac{100-21,57}{100} \cdot \frac{100-10}{100} \cdot \frac{100-10}{100} \cdot \frac{100-5}{100} \cdot \frac{100-15,83}{100} \\
& \mathrm{CCR}=25.000 \cdot 0,78 \cdot 0,9 \cdot 0,9 \cdot 0,95 \cdot 0,84 \\
& \mathrm{CCR}=12.604 \text { pessoas } / \text { dia }
\end{aligned}
$$


$\cdot \mathrm{CCF}$

$\mathrm{CM}=\frac{70 \cdot 100}{82}$

$\mathrm{CM}=85,36 \%$

$\mathrm{CCE}=\mathrm{CCR} \cdot \frac{\mathrm{CM}}{100}$

$\mathrm{CCE}=12604 \cdot \frac{85,36}{100}$

$\mathrm{CCE}=10.758$ pessoas $/ \mathrm{dia}$

A avaliação dos limites de capacidade de saturação surge, assim, como importante instrumento na prevenção de problemas (Novaes, 1998).

Segundo Wagar (apud Takahashi, 1997), a capacidade de carga recreativa é um conceito emprestado do manejo de pastagens e adaptado para buscar o número ideal de visitantes que uma área pode tolerar. Entretanto, reconheceu-se, com base na experiência, que a capacidade de carga não é um valor absoluto, resultado somente da avaliação das características ecológicas de cada área, e que muitos problemas advindos do uso para recreação não eram conseqüências do número de pessoas, mas do comportamento delas.

Os estudos ligados à capacidade de carga são ainda carentes de aparatos metodológicos: faltam modelos apropriados para a realidade brasileira (Xavier, 2002).

\section{Considerações finais}

Há outras metodologias de manejo mais específicas e eficazes para locais de uso turístico, contudo, são mais complexas, e exigem prazos maiores, maior número de dados e informações a respeito da área em estudo e investimentos (Moreira, 2003).

Podemos citar quatro métodos:

A. LAC ou Limite de Mudança Aceitável: desenvolvido por George Stankey, David Cole, Robert Lucas, Margaret Petersen e Sidney Frissell, para o Serviço Flo- restal dos Estados Unidos, publicado em 1985.

conceito de capacidade de suporte para fins turísticos, baseando-se mais nas condições desejáveis para áreas do que na quantidade de utilização que ela pode suportar.

B. Capacidade de carga de visitação recreativa em áreas protegidas: desenvolvido por Miguel Cifuentes, apresenta de forma sistemática pela primeira vez em 1992.

C. VIM ou Manejo de Impacto de Visitação: desenvolvido por Fred Kuss, Alan Graefe e Jerry Vaske, para a National Parks and Conservation Association USA (Associação de Parques Nacionais e Conservação dos EUA), publicado em 1990. Parte do princípio de que todo e qualquer tipo de visitação causa impacto. Portanto, a metodologia não busca a utopia do impacto "zero" e sim, mantê-lo em níveis aceitáveis a partir de determinados critérios, de acordo com os objetivos da área analisada.

D. Monitoramento e avaliação de projetos: modelo de matriz de monitoramento de projetos utilizado pela Interamerican Foundation - IAF. Elaborado com base no modelo VIM, refere-se aos serviços relativos à interpretação e aos visitantes. Foi idealizado para operar paralelamente ao processo de administração de um recurso natural (Moreira, 2003; Mitraud, 2003).

Cada um desses métodos dá mais ênfase às condições desejadas para as áreas naturais do que quanto ao uso que a área pode tolerar. Uma simples solução numérica é insuficiente para atender às necessidades de manejo das áreas naturais (Kinker, 2002).

O turismo em áreas naturais protegidas é, ainda hoje, um tema cheio de controvérsias, pois não é matéria fácil conciliar com a integridade da unidade o desejo dos governos em obter divisa, a ânsia dos empreendedores em participar da atividade e a demanda crescente por atividades de recreação intensiva, ao mesmo tempo que se façam cumprir os objetivos conservacionistas (Kinker, 2002).

A opção pelo desenvolvimento sustentável no Brasil por meio do ecoturismo requer ações conjuntas, organizadas e planejadas tanto em nível governamental como nos diversos segmentos do setor privado, baseadas em análises dos impactos ambientais e socioculturais (Ferreira \& Coutinho, 1999).

Por meio dos resultados obtidos, pode-se afirmar que a trilha do Paraíso apresenta boas condições de uso, onde sua vegetação de entorno agrada e motiva o visitante, despertando o contato com a natureza.

Com relação ao impacto ambiental na trilha do Paraíso, pode-se concluir que, segundo os dados obtidos, será considerada como trilha de pouquíssimo 
impacto na reserva biológica da Serra do Japi. Nota-se uma grande preocupação em conservar o ambiente e, ao mesmo tempo, realizar visitas para que o público conheça esta diversidade e também faça parte da conscientização em preservar a Serra.

Quanto à capacidade de carga, notou-se um número bastante elevado, resultando em uma grande capacidade de recepção de visitantes, sendo o valor apresentado superior ao número de pessoas que visitam a trilha hoje. Porém, esse número estabelecido não condiz com a realidade da trilha, sendo necessária a aplicação de um outro método mais específico.

Os resultados obtidos mostram que a trilha do Paraíso é um local que proporciona grande satisfação àqueles que saem da cidade e buscam um pouco de tranqüilidade em áreas verdes.

Ainda é importante ressaltar que, apesar dessa pesquisa abordar os impactos da visitação na região, não podemos esquecer que a atividade turística não é a única nem a maior responsável pela degradação do lugar, pois queimadas, desmatamentos irracionais, caça indiscriminada e desprezo pela questão da preservação por parte dos proprietários são, certamente, os grandes causadores dos principais danos às áreas naturais em geral, e também à Serra do Japi.

Para concluir, pode-se afirmar que os meios utilizados para a obtenção de informações sobre a Serra do Japi, e mais especificadamente sobre a trilha analisada, foram desgastantes, já que não havia qualquer dado-base sobre esse tipo de pesquisa que pudesse auxiliar na busca de informações concretas do local.

\section{Referências bibliográficas}

ANDRADE, W. J. 2003. Implantação e manejo de trilhas. In: MITRAUD, S. (Org.). Manual de ecoturismo de base comunitária: ferramenta para um planejamento responsável. Brasilia: wwF Brasil. p. 247-259.

BENI, M. C. 2001. Análise estrutural do turismo. 6. ed. São Paulo: SENAC.

BINELLI, A. A.; PINHO, A. M. \& MAGRO, T. C. 1997. Adaptação do método de Miguel Cifuentes para determinação da capacidade de carga em trilhas do município de Brotas - SP. In: CONGRESSO BRASILEIRO E UNIDADES DE CONSERVAÇĀO, 1997. Anais, v. 2 - Trabalhos técnicos. Curitiba: IAP/ UNILIVRE. p. 358-369.

BOO, E. 2001. O planejamento ecoturístico para áreas protegidas. In: LINDBERG, K \& HAWKINS, D. Ecoturismo: um guia para planejamento e gestão. São Paulo: SENAC. p. 31-57.

BRUSCHI, W. J. et al., 2002 Utilização dos elementos da paisagem como ferramenta de avaliação de impacto ambiental sobre o meio biótico. Caderno Biodiversidade, v. 3. nº 1, jan.

CADERNO DE PLANEJAMENTO. 2000. Serra do Japi. Jundiaí, v. 8, p. 49-58.
CANDIDO, L. 2003. Turismo em áreas naturais protegidas. Caxias do Sul: EDUCS.

CIFUENTES, M. 1992. Determinación de capacidad de carga turística en áreas protegidas. Série Técnica. Informe Técnico. Turrialba, Costa Rica: CaTIE. n. 194.

COOPER, C. et al. 2001. Turismo. Princípios e práticas. 2. ed. Porto Alegre: Bookmann.

DIAS, R. \& AGUIAR, M. R. 2002. Fundamentos do turismo: conceitos, normas e definiçōes. Campinas: Alínea.

EMBRATUR. 1994. Diretrizes para uma política nacional de ecoturismo. Brasília.

FARIA, H. H. \& LUTGENS, H. D. 1997. Estudo da capacidade de carga turística de uma área de recreação da Estação Experimental e Ecológica de Itirapina, São Paulo. In: CONGRESSO BRASILEIRO DE UNIDADES DE CONSERVAÇĀO, 1997. Anais, v. 2 - Trabalhos técnicos. Curitiba: IAP/UNILIVRE. p. 320-332.

FERREIRA, L. \& COUTINHO, M. 1999. Capacitação profissional em planejamento estratégico para o ecoturismo. Turismo em Análise. São Paulo: ECA-USP, v. 10, n² 2. p. 22-32.

KINKER, S. 2002.Ecoturismoe a conservação da natureza em parques nacionais. Campinas, SP: Papirus. LINDBERG, K \& HAWKINS, D. 2001. Ecoturismo: um guia para planejamento e gestão. São Paulo: SENAC.

MAGRO, T. C. 1999. Impactos de uso público em uma trilha no planalto do Parque Nacional de Itatiaia. Tese (Doutorado). São Carlos.

MITRAUD, S. (Org.). 2003. Manual de ecoturismo de base comunitária: ferramenta para um planejamento responsável. Brasília: wwF Brasil.

MOREIRA, C. M. B. 2003. Gestão do turismo: estudo de impacto ambiental e determinação de carga na trilha do rio Sapucaí. Relatório de Pesquisa. PUc-Campinas.

MORELLATO, P. C. 1992. História natural da Serra do Japi: ecologia e preservação de uma área no sudeste do Brasil. Campinas, SP: UnICAMP.

NOVAES, M. 2002. Atividades ecoturísticas e educação ambiental. In: BARRETO, M. \& TAMANINI, E. (Orgs.). Redescobrindo a ecologia no turismo. Caxias do Sul: EDUCS. p. 93-100.

. 1998. Turismo e política de planejamento sustentável. Revista de Negócios. Blumenau: FURB, v. 3, no 2, abr./jun, p. 35-40.

OLIVEIRA, C. S. \& ALVARENGA, G. S. P. 2002. Estudo da ecologia de paisagem em uma área de mineração desativada em função da implantação de atividades turísticas. Campinas, SP.

OLIVEIRA, F. 2003. Capacidade de carga nas cidades históricas. Campinas, SP: Papirus.

PEZOTTA, T. \& MARTOS, H. L. 2002. Análise ambiental das trilhas ecoturisticas da floresta nacional de Ipanema, Iperó, SP. Relatório de pesquisa. Sorocaba: PUC-SP.

RUSCHMANN, D. V. M. 1997. Turismo e planejamento sustentável: a proteção do meio ambiente. 7. ed. Campinas, SP: Papirus.

SEABRA, G. 2001. Ecos do turismo: o turismo ecológico em áreas protegidas. Campinas, SP: Papirus.

TAKAHASHI, L. 1997. Limite aceitável de câmbio - LAC: manejando e monitorando visitantes. In: CONGRESSO BRASILEIRO DE UNIDADES DE CONSERVAÇĀO, 1997. Anais, v. 1. Curitiba: IAP/UNILIVRE. p. 445-464. WEARING, M.C. 2001. Ecoturismo: impactos, potencialidades e possibilidades. São Paulo: Manole. 